\title{
Universidade Multicampi e o processo de interiorização da pós- -graduação stricto sensu: desafios e possibilidades
}

\author{
Angra Santos Porto, Marcius de Almeida \\ Gomes \& Sandra Gomes da Silva
}

\begin{abstract}
Resumo
O Plano Nacional de Pós-Graduação (PNPG - 2011-2020) trata da redução das disparidades regionais na oferta de Programas de Pós- Graduação Stricto Sensu no Brasil, a partir do diagnóstico e políticas estratégicas por mesorregiões. Nesse sentido, esta pesquisa investigou o processo de interiorização da pós-graduação stricto sensu da Universidade do Estado da Bahia (UNEB), no Território de Identidade Sertão Produtivo. Para isso, foi proposto o diagnóstico do perfil institucional, da percepção e dos discursos de professores (as) doutores (as), a respeito das condições acadêmicas, gerenciais e de infraestrutura para interiorização da pós-graduação stricto sensu na região, por meio da aplicação de formulário online e de entrevistas individuais e semiestruturadas, utilizando-se como técnica de análise o Discurso do Sujeito Coletivo (DSC). Os resultados apresentam discursos síntese, extraídos das expressões-chave, ideias centrais e/ou ancoragens, com base em indicadores relativos à percepção de como tem sido a atuação da Universidade, a importância da criação de programas e estratégias institucionais, as dificuldades, potencialidades, expectativas e proposições, que demonstram o potencial estratégico, os desafios e as possibilidades da UNEB e sua inserção no território para consolidar uma política institucional de interiorização.
\end{abstract}

Palavras-chave:

universidade multicampi; território; pós-graduação stricto sensu. 


\title{
Multicampi university and the post-graduation interiorization process stricto sensu: challenges and possibilities
}

\begin{abstract}
The National Postgraduate Plan (PNPG - 2011-2020) addresses the reduction of regional disparities in the offer of Stricto Sensu Graduate Programs in Brazil, based on the diagnosis and strategic policies by mesoregions. In this sense, this research investigated the process of interiorization of the stricto sensu postgraduate course of the State University of Bahia (UNEB), in the Territory of Sertão Productive Identity. For this, it was proposed the diagnosis of the institutional profile, the perception and the speeches of the teachers (as), regarding the academic, managerial and infrastructure conditions for the interiorization of the stricto sensu post-graduation in the region, through application of online form and individual and semi-structured interviews, using the Collective Subject Discourse (DSC) as the analysis technique. The results present synthesis discourses, extracted from the key expressions, central ideas and / or anchorages, based on indicators regarding the perception of how the University has been acting, the importance of the creation of the programs, institutional strategies, difficulties, potentialities, expectations and propositions that demonstrate the strategic potential, challenges and possibilities of the UNEB and its insertion in the territory to consolidate an institutional policy of interiorization.
\end{abstract}

Keywords: multicampi university; territory; postgraduate stricto sensu.

\section{Universidad multicampi y el proceso de interiorización de la post-graduación stricto sensu: desafíos y posibilidades}

Resumen: El Plan Nacional de Postgrado (PNPG - 2011-2020) trata de la reducción de las disparidades regionales en la oferta de Programas de Postgrado Stricto Sensu en Brasil, a partir del diagnóstico y políticas estratégicas por mesorregiones. En este sentido, esta investigación investigó el proceso de interiorización del postgrado stricto sensu de la Universidad del Estado de Bahía (UNEB), en el Territorio de Identidad Sertão Productivo. Para ello, se propuso el diagnóstico del perfil institucional, de la percepción y de los discursos de profesores (as) doctores (as), respecto a las condiciones académicas, gerenciales y de infraestructura para interiorización del postgrado stricto sensu en la región, la aplicación de formulario online y de entrevistas individuales y semiestructuradas, utilizando como técnica de análisis el Discurso del Sujeto Colectivo (DSC). Los resultados presentan discursos síntesis, extraídos de las expresiones clave, ideas centrales y / o anclajes, con base en indicadores relativos a la percepción de cómo ha sido la actuación de la Universidad, la importancia de la creación de programas, las estrategias institucionales, las dificultades, potencialidades, expectativas y proposiciones, que demuestran el potencial estratégico, los desafíos y las posibilidades de la UNEB y su inserción en el territorio para consolidar una política institucional de interiorización.

Palabras clave: universidad multicampi; territorio; postgrado stricto sensu.

\section{L'université multicampi et le processus d'interiorisation après le graduation stricto sensu: défis et possibilités}

Résumé: Le Plan national de formation postdoctorale (PNPG - 2011-2020) aborde la réduction des disparités régionales dans l'offre de programmes d'études supérieures de Stricto Sensu au Brésil, sur la base du diagnostic et des politiques stratégiques des mésorégions. En ce sens, cette recherche a porté sur le processus d'internalisation du cours de troisième cycle stricto sensu de l'Université d'État de Bahia (UNEB), dans le territoire de l'identité productive de Sertão. Pour cela, il a été proposé le diagnostic du profil institutionnel, de la perception et des discours des enseignants (es), en ce qui concerne les conditions académiques, managériales et d'infrastructure pour l'internalisation du stricto sensu post-graduation dans la région, à travers: application du formulaire en ligne et des entretiens individuels et semi-structurés, en utilisant le discours collectif (DSC) comme technique d'analyse. Les résultats présentent des discours de synthèse, extraits d'expressions clés, d'idées centrales et / ou d'ancrages, basés sur des indicateurs relatifs à la perception de la manière dont I'Université a agi, à l'importance de la création de programmes, aux stratégies institutionnelles, aux difficultés, aux potentialités, attentes et propositions qui démontrent le potentie stratégique, les défis et les possibilités de la UNEB et son insertion sur le territoire afin de consolider une politique institutionnelle d'internalisation.

Mots-clés: université multicampi; territoire; troisième cycle stricto sensu. 


\section{Introdução}

A definição de metas e estratégias para a redução das disparidades regionais na oferta da Pós-Graduação Stricto Sensu (PGSS) está presente nas políticas públicas de Educação Superior no Brasil. Nesse sentido, o Plano Nacional de Pós-Graduação (PNPG 2011-2020) aponta a necessidade do diagnóstico e de políticas estratégicas por mesorregiões.

Anísio Teixeira defendia a pós-graduação como estratégia fundamental para a renovação e reconstrução da universidade brasileira (Teixeira, 1989), nesse sentido, o I Plano Nacional de Pós-Graduação (1975), inspirado nessa concepção, já preconizava a necessidade de superação das diferenças regionais e de interiorização.

Com base nessa perspectiva, esta pesquisa investigou a percepção e os discursos de professores (as) doutores (as), a respeito do processo de interiorização da pós- graduação stricto sensu da Universidade do Estado da Bahia (UNEB), no Território de Identidade Sertão Produtivo1. A UNEB é uma instituição pública estadual, criada em 1983, e estruturada no modelo multicampi, pensado como estratégia para interiorizar o acesso à Educação Superior na Bahia.

A atuação da UNEB no Território destaca-se pela presença física de três Departamentos, que oferecem nove cursos de licenciatura e quatro cursos de bacharelado, deste modo, pressupõe-se o impacto gerado pela Universidade, bem como a demanda social por formação pós-graduada, além disso, trata-se da região do grande educador Anísio Teixeira, portanto, entende-se que o desenvolvimento educacional, inclusive com a oferta da pós-graduação stricto sensu, é uma forma de reafirmar sua história e consolidar sua luta por uma educação pública, gratuita e de qualidade, em todos os níveis formativos.

Deste modo, o estudo organiza-se pela introdução, um breve referencial teórico sobre a relação Universidade Multicampi, Território e a Pós-Graduação Stricto Sensu. Logo após, apresenta uma síntese do percurso metodológico e, por fim, os resultados, discussões e as considerações finais, acerca dos desafios e as possibilidades da UNEB para a interiorização da pós-graduação stricto sensu na região.

\section{Universidade, Território e a Pós-Graduação Stricto Sensu}

A década de 1980, caracterizou-se como um período em que as políticas públicas de expansão e interiorização da Educação Superior no Brasil assumiram novos contornos e particularidades, com destaque para o processo de privatização (Dourado, 2001). A UNEB foi criada nesse contexto, o que marca um diferencial, por tratar-se de uma instituição pública, de iniciativa do poder público estadual. 
A organização multicampi revela desafios e peculiaridades decorrentes das dimensões acadêmicas, espaço-temporais e funcionais, que implicam no desenvolvimento das atividades e projetos e influenciam na estrutura organizacional e, consequentemente, na gestão (Fialho, 2009; Pimenta, 2007; Barbosa, 2016).

Para Fialho (2005, p. 74), o compromisso com a interiorização do acesso à Educação Superior pela universidade multicampi, envolve uma série de desafios, inclusive a superação da restrição de sua atuação ao ensino, "[...] A permanência da universidade multicampi em lugares que não asseguram o seu próprio desenvolvimento não se pode transformar numa obrigatoriedade vazia, sem retorno social".

Nesse sentido, o processo de interiorização do acesso à Educação Superior, para além do ensino, requer infraestrutura material e humana, para adentrar realidades de desafios, caso contrário, poderá enfrentar dificuldades em lugares que não oferecem condições para o desenvolvimento da pesquisa e da pós-graduação (Fialho, 2009).

No estudo supracitado, a autora demonstra a pertinência da categoria espaço/ território para analisar os desequilíbrios regionais no contexto da pesquisa e da pós- graduação em educação no Brasil, com base em estudos de Milton Santos, na perspectiva da nova geografia, que entende o território usado pela sociedade como criação do espaço, que envolve todos os atores e aspectos.

As configurações territoriais são o conjunto dos sistemas naturais, herdados por uma determinada sociedade, e dos sistemas de engenharia, isto é, objetos técnicos e culturais historicamente estabelecidos. As configurações territoriais são apenas condições. Sua atualidade, isto é, sua significação real advém das ações realizadas sobre elas (Santos \& Silveira, 2008, p. 248).

Para Fialho (2009), a inserção da universidade num dado espaço físico-geográfico possui relação com o processo de urbanização e de industrialização do País, assim, as diferenças entre regionais e intra-estaduais "[...] manifestarão, com relação à expansão ou à interiorização [...], os efeitos desses mesmos processos, em decorrência dos indicadores econômicos e sociais, de áreas metropolitanas ou não metropolitanas, urbanas ou rurais" (Fialho, 2009, p. 24).

Tal posicionamento remete à noção de desigualdade territorial, que tem se ampliado nos últimos anos. Nesse contexto, a região Nordeste do Brasil vivencia a realidade de uma estrutura fundiária que dificulta a distribuição de renda, a redução dos índices de pobreza e a urbanização [...] "Por isso a introdução de inovações materiais e sociais iria encontrar a grande resistência de um passado cristalizado na sociedade e no espaço atrasando o processo de desenvolvimento. (Santos \& Silveira, 2008, p. 275).

Desta forma, os autores supracitados enfatizam o impacto da prática do neoliberalismo na utilização do território, cuja seletividade acaba punindo "as populações mais 
pobres, mais isoladas, mais dispersas e mais distantes dos grandes centros e dos centros produtivos (Santos \& Silveira, 2008, p. 302).

[...] a distribuição dos programas de pós-graduação reconhecidos pela CAPES por Unidade da Federação [...], identifica que os estados das regiões Sul e Sudeste apresentam as maiores concentrações de programas de pós-graduação, e também identifica uma menor concentração nos estados das regiões Norte, Nordeste e Centro-Oeste. Entretanto, a mesma análise - considerando as mesorregiões brasileiras - identifica as maiores concentrações de programas de pós-graduação nas regiões metropolitanas de quase todos os estados, principalmente as litorâneas (PNPG - 2011-2020, BRASIL, 2010, p. 146).

Deste modo, o processo de interiorização da pós-graduação stricto sensu como uma política pública, deve considerar as diferentes realidades e o contexto de desigualdade do País, para assim, desenvolver estratégias condizentes com as possibilidades institucionais e regionais para a redução das disparidades. Nessa perspectiva, o estudo proposto busca reconhecer o potencial do Território de Identidade Sertão Produtivo e investigar os desafios e as possibilidades que se abrem para a atuação da UNEB nesta região.

\section{Procedimentos Metodológicos}

Este artigo resulta de uma pesquisa de campo, realizada em três Departamentos da UNEB, situados em municípios no Território de Identidade Sertão Produtivo (Guanambi, Caetité e Brumado), por meio do preenchimento de formulário online e entrevistas individuais e semiestruturadas, realizou-se o diagnóstico do perfil institucional, da percepção e dos discursos de professores (as) doutores (as) da Universidade, na região estudada.

De um universo de quarenta e dois professores (as) doutores (as), pertencentes ao quadro permanente da UNEB nos Departamentos pesquisados, vinte e dois responderam ao formulário online, e, destes, onze foram selecionados e convidados para participar da entrevista, considerando os seguintes critérios: um professor por curso; experiência com gestão e tempo de universidade.

Para análise, utilizou-se a técnica do Discurso do Sujeito Coletivo (DSC), um processo complexo de análise de dados qualitativos, coletados verbalmente, por meio de depoimentos, a partir dos quais são extraídas as Expressões-Chave (E-Ch), as Ideias Centrais (ICs) e/ou as Ancoragens (ACs), para então produzir um ou vários discursos-síntese, que compõem os Discursos do Sujeito Coletivo (DSCs) (Lefevre \& Lefevre, 2005). 


\section{Resultados e Discussões}

\subsection{Diagnóstico do Perfil Institucional dos Sujeitos Pesquisados}

De um total de quarenta e dois professores (as) doutores (as), vinte e dois responderam ao formulário online. Entre estes, observou-se que a maioria possui o tempo de universidade entre 11 e 20 anos, atua em regime de Dedicação Exclusiva e concluiu o doutorado a partir de 2012. Foram bolsistas de doutorado $(81,82 \%)$, possui experiência com orientação de IC (100\%) e com desenvolvimento de projetos de pesquisa (100\%).

A Coordenação de Aperfeiçoamento de Pessoal de Nível Superior (CAPES) é a instituição responsável pela avaliação dos cursos de pós-graduação do Brasil e pelo reconhecimento e aprovação de novos cursos, que podem ser propostos por universidades faculdades ou centros de pesquisa (Almeida \& Guimarães, 2013).

Entre os requisitos exigidos pela Portaria $n^{\circ} 161$, de 22 de agosto de 2017, que trata da avaliação de Propostas de Cursos Novos, APCN, de pós-graduação stricto sensu, encontra-se a competência e qualificação acadêmica, didática, técnica e/ou científica do grupo proponente e quadro de docentes permanentes suficiente e em condições de assegurar a regularidade e a qualidade das atividades de ensino, pesquisa e orientação científica.

\subsection{Condições Acadêmicas, Gerenciais e de Infraestrutura}

A Tabela 1 apresenta a avaliação das condições acadêmicas, gerenciais e de infraestrutura para o processo de interiorização da PGSS da UNEB.

$\mathrm{Na}$ avaliação das "condições acadêmicas" para o processo de interiorização da PGSS, observou-se que o apoio para produção e difusão do conhecimento, as iniciativas para constituição de redes acadêmicas e o processo de internacionalização apresentaram maiores frequências para avaliação negativa (regular e ruim), com valores acima de $85 \%$.

Quanto às "condições gerenciais" a Política Institucional para Pesquisa e Pós Graduação e o Fomento de Editais apresentaram maiores frequências para avaliação negativa (regular e ruim), com valores acima de $80 \%$. Já para as "condições de infraestrutura" todos os indicadores obtiveram frequências negativas acima de 85\%.

Estas condições foram sistematizadas com base nas exigências normativas da CAPES para criação de novos cursos e, para além disso, considerando as estratégias institucionais que podem ser desenvolvidas para incentivar o crescimento e a consolidação da pesquisa e pós-graduação. 
Tabela 1- Avaliação das condições acadêmicas, gerenciais e de infraestrutura para o processo de interiorização Pós-Graduação Stricto Sensu da UNEB

\begin{tabular}{|c|c|c|c|c|c|c|}
\hline Variáveis / Indicadores & \multicolumn{2}{|c|}{ BOM } & \multicolumn{2}{|c|}{ REGULAR } & \multicolumn{2}{|c|}{ RUIM } \\
\hline Condições Acadêmicas & $\mathbf{F}$ & $\%$ & $\mathbf{F}$ & $\%$ & $\mathbf{F}$ & $\%$ \\
\hline Disponibilidade de carga horária docente & 6 & 27,27 & 12 & 54,55 & 4 & 18,18 \\
\hline $\begin{array}{l}\text { Apoio para produção e difusão do } \\
\text { conhecimento }\end{array}$ & 2 & 9,09 & 15 & 68,18 & 5 & 22,73 \\
\hline $\begin{array}{l}\text { Iniciativas para constituição de redes } \\
\text { acadêmicas }\end{array}$ & 3 & 13,64 & 13 & 59,09 & 6 & 27,27 \\
\hline Processo de internacionalização & 1 & 4,55 & 11 & 50,00 & 10 & 45,45 \\
\hline Estímulos a parcerias institucionais & 4 & 18,18 & 7 & 31,82 & 11 & 50,00 \\
\hline Condições Gerenciais & $\mathbf{F}$ & $\%$ & $\mathbf{F}$ & $\%$ & $\mathbf{F}$ & $\%$ \\
\hline $\begin{array}{l}\text { Apoio das instâncias de Gestão Central } \\
\text { UNEB }\end{array}$ & 06 & 27,27 & 11 & 50,00 & 5 & 22,73 \\
\hline $\begin{array}{l}\text { Apoio da Gestão Departamental } \\
\text { (NUPE/Direção) }\end{array}$ & 11 & 50,00 & 10 & 45,45 & 1 & 4,55 \\
\hline $\begin{array}{l}\text { Política Institucional para Pesquisa e Pós } \\
\text { Graduação }\end{array}$ & 03 & 13,64 & 16 & 72,73 & 3 & 13,64 \\
\hline Fomento de Editais & 01 & 4,55 & 14 & 63,64 & 6 & 27,27 \\
\hline Condições de Infraestrutura & $\mathbf{F}$ & $\%$ & $\mathbf{F}$ & $\%$ & $\mathbf{F}$ & $\%$ \\
\hline Espaço físico adequado para pesquisa & 2 & 9,09 & 4 & 18,18 & 16 & 72,73 \\
\hline Disponibilidade de laboratórios & 3 & 13,64 & 12 & 54,55 & 7 & 31,82 \\
\hline Disponibilidade de equipamentos & 2 & 9,09 & 12 & 54,55 & 8 & 36,36 \\
\hline Disponibilidade de material didático & 1 & 4,55 & 17 & 77,27 & 4 & 18,18 \\
\hline
\end{tabular}

Obs.: para o item "Fomento de Editais" houve uma não resposta.

Com base na percepção dos (as) doutores (as) é possível inferir que existe a necessidade de uma atuação mais efetiva por parte da gestão universitária, no sentido de apresentar estratégias de melhoria e ampliação das ações para o fortalecimento de uma política institucional de interiorização da pós-graduação.

De acordo com Fialho (2009), o desenvolvimento da pesquisa e da pós-graduação stricto sensu requer infraestrutura adequada, não somente relativa ao espaço físico, bibliotecas e laboratórios, mas também à titulação docente, oferta de pós-graduação stricto sensu e produção intelectual institucionalizada, além disso, acrescenta que a universidade está sujeita a variáveis do contexto regional e urbano.

“[...] A inserção da universidade no território traduz, como um mapa que se dá em testemunho, as zonas de concentração e as zonas de escassez em termos de competências acadêmicas, científicas e tecnológicas" (Fialho, 2009, p. 31). 


\subsection{O Discurso do Sujeito Coletivo (DSC)}

A partir de entrevistas individuais e semiestruturadas, realizadas com onze professores (as) doutores (as), com base em indicadores que permitiram a definição das categorias de análise (Quadro 1), foi realizada a transcrição e a leitura minuciosa das respostas, extraindo as expressões-chave e as ideias centrais, para a produção dos DSCs.

Quadro 1 - Síntese das Categorias de Análise

\begin{tabular}{|c|c|}
\hline INDICADORES & IDEIAS CENTRAIS \\
\hline $\begin{array}{l}\text { Percepção dos (as) professores (as) sobre o } \\
\text { processo de interiorização desenvolvido pela } \\
\text { UNEB. }\end{array}$ & $\begin{array}{l}\text { A UNEB não tem cumprido o papel de } \\
\text { interiorizar a Educação Superior. } \\
\text { A UNEB é pioneira em muitas regiões da } \\
\text { Bahia e tem cumprido o papel de interiorizar } \\
\text { a Educação Superior no Estado. }\end{array}$ \\
\hline $\begin{array}{l}\text { Importância da criação de um Programa de } \\
\text { Pós-Graduação Stricto Sensu na região. }\end{array}$ & $\begin{array}{c}\text { É muito importante para a Universidade. } \\
\text { É importante para a região e para a formação } \\
\text { de profissionais. }\end{array}$ \\
\hline $\begin{array}{c}\text { Conhecimento de estratégias institucionais } \\
\text { para interiorização da pós-graduação stricto } \\
\text { sensu. }\end{array}$ & $\begin{array}{l}\text { Conhece algumas ações institucionais. } \\
\text { Não conhece estratégias institucionais. }\end{array}$ \\
\hline $\begin{array}{l}\text { Avaliação das possibilidades de atuação } \\
\text { e contribuição para o processo de } \\
\text { interiorização e fortalecimento da pós- } \\
\text { graduação stricto sensu. }\end{array}$ & Responsabilidade Social e Profissional \\
\hline $\begin{array}{l}\text { Principais dificuldades e potencialidades para } \\
\text { o desenvolvimento e o fortalecimento da } \\
\text { pós-graduação stricto sensu. }\end{array}$ & $\begin{array}{l}\text { Necessidade de políticas de incentivo e } \\
\text { condições de trabalho. } \\
\text { Força de vontade, desejo, envolvimento e } \\
\text { engajamento. }\end{array}$ \\
\hline $\begin{array}{l}\text { Expectativas e proposições para a } \\
\text { consolidação do processo de interiorização } \\
\text { da pós-graduação stricto sensu na região. }\end{array}$ & $\begin{array}{l}\text { A Universidade está caminhando para } \\
\text { mudanças e fortalecimento do processo de } \\
\text { interiorização. }\end{array}$ \\
\hline
\end{tabular}

Fonte: Elaborado pelos autores, adaptado de Pinto e Kosby (2018)

\section{O processo de interiorização desenvolvido pela UNEB}

Ideia Central: A UNEB não tem cumprido o papel de interiorizar a Educação Superior. 
DSC: [...] Eu acredito que a UNEB ainda não tem cumprido esse papel de interiorizar a Educação Superior, pois a pós-graduação ainda está concentrada em Salvador, no campus I e nos Departamentos do entorno de Salvador. [...] A UNEB tem tradição mais de ensino, de cursos de licenciatura, de graduação, mas a pós-graduação e a interiorização da pós-graduação ainda precisa acontecer.

Ao tratar da UNEB, Fialho (2005) destaca a prevalência do ensino de graduação nos campi do interior, em detrimento do ensino e oferta de cursos de pós-graduação stricto sensu, pesquisa e extensão universitária. Para a autora, essas lacunas provocam prejuízos para a instituição e para a sociedade das regiões localizadas nos municípios geograficamente mais distantes da capital.

Barbosa (2016) ressalta o importante papel da universidade com a formação de profissionais para a Educação Básica, além da democratização possibilitada pela organização multicampi, mas reconhece o distanciamento quanto à formação continuada e em nível de pós-graduação destes profissionais, evidenciando, portanto, a lacuna em relação à interiorização da PGSS.

Ideia Central: A UNEB é pioneira em muitas regiões da Bahia e tem cumprido o papel de interiorizar a Educação Superior no Estado.

DSC: [...] A UNEB se inseriu praticamente como pioneira em muitas regiões da Bahia. [...] Eu percebo que ela tem avançado nos últimos anos, há um claro movimento em direção a capacitar o docente, principalmente o docente do interior que não têm acesso fácil aos cursos de mestrado e doutorado, porque são concentrados nas capitais. Além disso, a política de interiorização da UNEB é uma possibilidade de acesso a muitos que não tem ou não teriam condição de ir para as capitais. [...] Eu acho que a UNEB tem esse papel desbravador, de disseminação da informação, principalmente da formação docente, fora do eixo de dominação do capital na Bahia.

O pensamento internalizado no discurso revela o quanto a UNEB tem contribuído para a interiorização do acesso à Educação Superior no Estado da Bahia, embora existam fragilidades no pleno desenvolvimento de suas ações finalísticas, a Universidade se insere em territórios e regiões desassistidas e destaca-se pelo pioneirismo e bravura.

"A ideia de universidade multicampi foi se consolidado como uma expressão de compromisso com as realidades regionais" (Fialho, 2005, p. 96). A pesquisa realizada por Barbosa (2013), demonstra as contribuições da UNEB para 
a educação da Bahia e também de outros Estados e o impacto da presença das instituições de Educação Superior para o desenvolvimento econômico e social dos municípios. Portanto, a trajetória histórica da UNEB é reconhecida pelo papel desempenhado a nível de ensino de graduação, mas a instituição tem conduzido de forma progressiva a ampliação de sua atuação.

Importância da criação de um programa de PGSS na região

Ideia Central: É muito importante para a Universidade.

DSC: [...] Eu acho muito importante, pois a universidade tem o seu tripé ensino, pesquisa e extensão e a pesquisa no interior realmente é bem difícil, espero que a UNEB atinja ao longo do tempo, uma estrutura a nível de grupo, condições laboratoriais bem aprimoradas, além de políticas de pesquisa e Iniciação Científica, pesquisa a nível de pós-graduação: especialização, mestrado e doutorado, não só na capital mas em todos os campi.

Com base no Parecer CNE/CES n 977/1965, que regulamentou a pós-graduação no Brasil, observa-se que cumprimento efetivo da pós-graduação stricto sensu está associado à própria condição de universidade, o que implica na necessidade de buscar alternativas para o seu pleno desenvolvimento.

Ideia Central: É importante para a região e para a formação de profissionais.

DSC: [...] Eu considero fundamental, porque a região tem muita coisa a ser pesquisada e a implantação de um curso de mestrado no interior dinamizaria demais os cursos e representa a valorização dos profissionais que passaram pela área de licenciatura, que precisam se capacitar e não precisariam mudar da região. Além disso, é uma forma de valorizar as demandas regionais, ajudando intencionalmente na melhoria da nossa comunidade e quando a gente torna isso tudo nucleado em Salvador, não é a mesma coisa.

Observa-se o destaque da UNEB no Território de Identidade Sertão Produtivo no campo das licenciaturas, bem como a expectativa de possibilitar a continuidade da formação destes profissionais, além disso, a pós-graduação stricto sensu representa a possibilidade ampliar as pesquisas no contexto regional.

De acordo com Dourado (2016, p. 28), o debate acerca da formação inicial e continuada, bem como da valorização de profissionais do magistério da educação básica têm se acentuado na última década. Nesse sentido, as proposições do Plano Nacional de Pós-Graduação (PNPG 2011-2020), contempladas no Plano Nacional de Educação (PNE 2014-2024), sinalizam para uma aproximação cada vez maior entre as etapas 
formativas da Educação Básica e Educação Superior, como meio de fortalecer e consolidar a ideia de sistema nacional de educação, cuja base exerce influência significativa para os caminhos posteriores.

Recentemente, a UNEB aprovou a criação e implantação do Programa de Pós-Graduação Stricto Sensu em Ensino, Linguagem e Sociedade, no Departamento de Ciências Humanas (DCH - Campus VI), na cidade de Caetité, o que demonstra que a Universidade tem investido esforços para viabilizar o processo de interiorização da PGSS.

\section{Estratégias institucionais para interiorização da PGSS \\ Ideia Central: Conhece algumas ações institucionais.}

DSC: A aprovação de dois DINTER, o apoio da Universidade, a manutenção de bolsas, a Iniciação Científica, isso é preciso registrar como um processo de interiorização. Além disso, o incentivo a parcerias da universidade com outras instituições, a internacionalização do Ensino Superior chegando para o interior, então a UNEB está correndo atrás e buscando estratégias de voltar aos campi, criar os mestrados e, posteriormente, o doutorado.

Observa-se que a Universidade tem desenvolvido ações para desenvolver o processo de interiorização da pós-graduação stricto sensu, que constitui-se como um objetivo institucional presente em seu Plano de Desenvolvimento Institucional (PDI UNEB 2017-2022), em consonância com as estratégias propostas nas políticas públicas educacionais, como o Plano Nacional de Educação (PNE 2014-2024) e o Plano Nacional de Pós-graduação (PNPG 2011-2020).

Ideia Central: Não conhece estratégias institucionais.

DSC: Eu ainda não conheço, a gente já teve algumas iniciativas, mas muito tímidas, tem o edital do PROFORTE, mas tem uma descontinuidade, isso dificulta a fixação de docentes na região e a estruturação dos grupos de pesquisa, para a geração dos cursos de pós-graduação. Na verdade, a iniciativa de criação de um programa é dos professores, nós estamos nos unindo, vendo essa necessidade, a gente também está se qualificando e temos esse compromisso social e científico de dar continuidade nos estudos. Não estou dizendo que a gestão não apoia, mas o que eu percebo é que há um esforço muito maior de quem está aqui, pois desconheço algo mais sistemático, mais organizado, mais elaborado. 
Percebe-se a lacuna na definição de uma política institucional, pautada em ações planejadas e sistematizadas com objetivos e metas bem definidas e de acordo com a realidade de cada território. Desta forma, observa-se a necessidade de pensar um plano estratégico por regiões, que reconheça as diferentes realidades dos territórios e norteie as ações da Universidade, além de oferecer um maior suporte acadêmico, gerencial e de infraestrutura para os Departamentos.

\section{Possibilidades de atuação e contribuição para o processo de interiorização e fortalecimento da PGSS}

Ideia Central: Responsabilidade Social e Profissional

DSC: Ao refletir essa questão eu me coloco mesmo como parte do processo e vejo que sou corresponsável, então eu preciso dar a minha contribuição como pesquisadora, como profissional e também como cidadã. Além disso, eu considero importante dar o retorno social pelo investimento feito pela Universidade na minha formação, estimular os professores a buscarem uma qualificação maior, não apenas como forma de incentivo de produtividade, mas como respaldo na sua formação, incentivar e preparar também os alunos, compor o quadro docente de pós-graduação e contribuir com a formação dos profissionais na região.

Observa-se o reconhecimento e a responsabilidade dos (as) professores (as), numa perspectiva democrática de cidadania. Deste modo, numa perspectiva de universidade enquanto institucional social (Chauí, 2003), importa considerar a relevância do compromisso social que o profissional assume no exercício de sua função.

\section{Dificuldades e potencialidades para o desenvolvimento e o fortalecimento da PGSS}

Ideia Central: Necessidade de políticas de incentivo e condições de trabalho.

DSC: Eu percebo a sobrecarga de trabalho dos professores doutores nas atividades de ensino, que implica no tempo e disponibilidade para realização de pesquisas. Além disso, tem a falta de participação nas reuniões e envolvimento coletivo; a dificuldade de fixação dos doutores; a questão estrutural de espaço físico, transporte, biblioteca; o quadro de professores e de técnicos reduzido; a baixa produtividade docente em revistas indexadas; carência de investimentos para viabilizar mais a participação em eventos; carência de recursos para pesquisa; falta de incentivo à publicação e a dificuldade de interiorizar mesmo, pois fica tudo centralizado em Salvador. Eu percebo ainda que a UNEB, no campus I 
e outros campi não têm uma abertura maior para poder acolher os professores doutores do interior, ajudando nessa questão da produção do conhecimento.

Pimenta (2007) expõe que a grande problemática de uma instituição universitária multicampi para se qualificar como universidade consiste na promoção da titulação docente e na oferta de programas de pós-graduação nos diversos campi, em meio as dificuldades como a fixação de doutores e a falta de infraestrutura adequada para pesquisa. Além disso, de acordo com Fialho (2005), os professores doutores não possuem condições para produção acadêmica e científica, assim, muitos partem em busca de outros ambientes de trabalho, ou restringem suas atividades ao exercício do ensino.

Ideia Central: Força de vontade, desejo, envolvimento e engajamento.

DSC: Eu vejo que nós temos professores com formação e produções relevantes, temos os estímulo do Departamento, estamos fortalecendo a criação de revistas científicas, pesquisas fantásticas sendo desenvolvidas e temos muito ainda a ser pesquisado, a ampliação considerável do número de estudantes envolvidos com a Iniciação Científica, a aprovação de dois DINTER na região, o envolvimento de alguns professores em programas de pós-graduação de outras instituições, como por exemplo da UESB e, sobretudo, eu acho que o nosso maior potencial é a vontade dos professores, o compromisso social com a comunidade e com os egressos nos instiga ao desejo, envolvimento e engajamento.

Para Barbosa (2016, p. 101), "é preciso pensar a Universidade do Estado da Bahia em meio às contradições e tensões existentes entre o desempenhar de suas funções tradicionais e os novos desafios que a contemporaneidade lhe apresenta". Nesse sentido, o discurso ora apresentado revela que, mesmo diante das dificuldades, existe um empenho por parte dos docentes.

\section{Expectativas e proposições para a consolidação do processo de interiorização da PGSS}

Ideia Central: A Universidade está caminhando para mudanças e fortalecimento do processo de interiorização.

DSC: Eu vejo que a Pró-Reitoria de Ensino de Pós-Graduação e Pesquisa está se organizando melhor, está tendo uma visão mais de universidade, pois hoje tem mais ações voltadas para o interior, [...] eu acredito na aprovação do programa de pós-graduação stricto sensu para nossa região [...] e vejo um futuro próximo em que a UNEB terá um reconhecimento maior para o interior 
do Estado, eu acho que a gente tá vivendo um momento muito ruim político-econômico, mas a gente tem um grupo que tem uma possibilidade grande de se levantar em prol da diminuição das nossas vulnerabilidades. [...] Como proposição eu acho que a realização de intercâmbio na oferta dos programas de pós-graduação entre os Departamentos, como acontece na graduação, em forma de cooperação interdepartamental e um maior suporte da universidade para os grupos de pesquisa, por meio de políticas de financiamento. Além disso, eu acho que a gente tem que ter coragem de se arriscar, de tentar, de fazer [...] Penso ainda que a gente precisa manter um diálogo contínuo com a comunidade.

Observa-se que a superação das dificuldades para o desenvolvimento da PGSS perpassam questões que demandam ações e estratégias institucionais planejadas e sistematizadas. Nesse sentido, o PNPG 2011-2020 aponta a necessidade de apoio e fortalecimento aos grupos emergentes, a fim de reduzir número de mesorregiões sem programas, docentes e bolsas de pós-graduação stricto sensu.

\section{Considerações Finais}

Os resultados da pesquisa demonstram os desafios e as possibilidades da UNEB, por sua organização multicampi e inserção nos território, para o processo de interiorização da PGSS. Com base na percepção e nos discursos dos sujeitos pesquisados, o desenvolvimento de programas de pós-graduação stricto sensu na região, constitui-se como uma ação de responsabilidade social, para atender à demanda formativa de egressos e profissionais, e também profissional, como forma de retorno social e institucional do investimento feito pela Universidade para a qualificação do quadro de doutores.

Nota-se que as ações desenvolvidas pela Universidade para a interiorização da pós-graduação não são compreendidas como estratégias institucionais, devido à falta de uma sistematização e da efetivação de uma política institucional que promova o incentivo à pesquisa, a produção de conhecimentos e, consequentemente, ao fortalecimento dos grupos de pesquisa e a legítima interiorização.

Assim, dentre as dificuldades para a efetivar o processo de interiorização, destaca-se a inexistência de políticas de incentivo e a falta de condições para o desenvolvimento da pesquisa, uma vez que os pesquisadores se veem diante de um quadro insuficiente de profissionais para atender às demandas de ensino, o que implica em sobrecarga de trabalho, e/ou ao não desenvolvimento de pesquisas.

A força de vontade e o engajamento de alguns professores destaca-se como principal potencialidade relatada nos discursos, o que pode ser confirmado pelos resultados 
alcançados a partir de iniciativas dos Departamentos, com o apoio da Administração Central, como o crescimento expressivo do número de projetos de Iniciação Científica, a oferta de dois cursos de Doutorado Interinstitucional, bem como a criação e implantação de um Programa de Pós-Graduação Stricto Sensu.

Portanto, observa-se que UNEB está consolidada no papel de interiorizar o acesso à Educação Superior no Estado, no entanto, a própria condição de universidade exige o repensar de suas ações, planejamento e organização de uma política institucional, organizada com base nos indicadores que envolvem as dimensões acadêmicas, gerenciais e de infraestrutura para a oferta de programas de pós-graduação stricto sensu.

\section{Notas}

1 Considera-se Território de Identidade, o agrupamento identitário municipal formado de acordo com critérios sociais, culturais, econômicos e geográficos, e reconhecido pela sua população como o espaço historicamente construído ao qual pertence, com identidade que amplia as possibilidades de coesão social e territorial (BAHIA, 2010).

\section{Referências}

Almeida, E.C. E. de; Guimarães, J.A. (2013). A Pós-Graduação e a Evolução da Produção Científica Brasileira. São Paulo: Editora Senac.

Barbosa, E. R. O. (2016). A Presença da Universidade do Estado da Bahia nos Meios Locais: o perfil e a inserção profissional dos seus egressos licenciados. Tese de Doutoramento. Salvador: Universidade do Estado da Bahia (UNEB).

Barbosa, C. (2013). Financiamento público das universidades estaduais baianas: restrições orçamentárias, expansão universitária e desenvolvimento local. Tese de Doutoramento. Salvador: Universidade do Estado da Bahia (UNEB).

Chaui, M. (2003). A Universidade Pública sob Nova Perspectiva. Revista Brasileira de Educação, 24, 05-15.

Decreto n 12.354 , de 25 de agosto de 2010. (2010). Institui o Programa de Territórios de Identidade e dá outras providências. Diário Oficial Salvador, 25 de agosto, 2010. Recuperado em 04 de janeiro, 2018, de <http://www.jusbrasil.com.br/legislacao/1024959/decreto-12354-10-bahia-ba>.

Dourado, L. F. (2001) A Interiorização da Educação Superior e a Privatização do Público. Goiânia: Ed. da UFG.

Dourado, L. F. (2016). Formação de profissionais do magistério da educação básica: novas diretrizes e perspectivas. Comunicação \& Educação, 21, 27-39. Recuperado em 03 de novembro, 2017, de $<$ http://www.revistas.usp.br/comueduc/article/view/110712/112709>.

Fialho, N. H. (2005). Universidade Multicampi. Brasilia: Plano Editora.

Fialho, N. H. (2009). Chão Desigual: A categoria espaço/território no contexto da pesquisa e da pósgraduação em educação no Brasil. In: A. D. Nascimento \& T. M. Hetkowski, (Org.) Educação e contemporaneidade: pesquisas científicas e tecnológicas (pp. 19-39). Salvador: Edufba. 
Lefevre. F.; \& Lefevre. A.M. C. (2005) Depoimentos e Discursos: uma proposta de análise em pesquisa social. Brasília: Liber Livro Editora.

Parecer no 977/65. (1965). Conselho Federal de Educação. Definição dos cursos de pós-graduação. Brasília, DF, 1965. Recuperado em 01 de junho, 2017, de <http://www.capes.gov.br/images/ stories/download/avaliacao/avaliacao-n/Parecer-977-1965.pdf>.

Pimenta. L. B. (2007). Processo Decisório na Universidade Multicampi: dinâmica dos Conselhos Superiores e Órgãos de Execução. Tese de Doutoramento. Salvador: Universidade do Estado da Bahia (UNEB).

Plano de Desenvolvimento Institucional (PDI) UNEB quadriênio 2017-2022. (2017). Salvador. Recuperado em 03 de maio, 2018, de https://portal.uneb.br/proplan/wp-content/uploads/sites/64/2018/03/ PDI_2017_2022-.pdf.

Plano Nacional de Educação PNE 2014-2024 Linha de Base. Instituto Nacional de Estudos e Pesquisas Educacionais Anísio Teixeira. (2015). Brasília - DF. INEP. Recuperado em 05 de julho, 2017, de $<$ http://www.publicacoes.inep.gov.br/portal/download/1362>.

Plano Nacional de Pós-Graduação (PNPG) 2011-2020. (2010). Ministério da Educação (MEC). Brasília, CAPES, Brasília, 2010. Recuperado em 30 de maio, 2017, de < http://www.capes.gov.br/planonacional-de-pos-graduacao>.

Pinto, R. S; \& Kosby, A.A. (2018). O Papel do Administrador na Estrutura Acadêmica da Universidade Federal do Rio Grande: uma Análise do Discurso do Sujeito Coletivo. Revista GUAL, 11, 01-22.

Santos, M.; \& Silveira, M. L. (2008). O Brasil: território e sociedade no início do século XXI. 8. ed. São Paulo: Record.

Teixeira, A. (1989). Ensino Superior no Brasil: análise e interpretação de sua evolução até 1969. Rio de Janeiro: Editora da Fundação Getúlio Vargas.

Angra Santos Porto

Mestranda do Programa de Pós-Graduação em Gestão e Tecnologias Aplicadas à Educação (MP GESTEC), da Universidade do Estado da Bahia (UNEB)

E-mail: angrasporto@gmail.com

\section{Marcius de Almeida Gomes}

Doutor em Educação Física na Área da Atividade Física e Saúde, pela Universidade Federal de Santa Catarina (2012); Professor Titular da Universidade do Estado da Bahia (UNEB/ Campus XII); Professor do Programa de Pós Graduação Gestão e Tecnologias Aplicadas à Educação

(MP GESTEC).

E-mail: magomes@uneb.br 
Sandra Célia Coelho Gomes da Silva

Pós-Doc em Educação e Contemporaneidade, pela Universidade do Estado da Bahia (UNEB); Professora Ajunta da UNEB/Campus XII; Coordenadora do Mestrado Profissional em Intervenção Educativa e Social (MPIES -

UNEB/Campus XI).

E-mail: scsilva@uneb.br

Correspondência

Sandra Célia Coelho Gomes da Silva Universidade do Estado da Bahia Campus XII - Guanambi

Data de submissao: Dezembro 2019 Data de avaliação: Fevereiro 2020

Data de publicação: Novembro 2020 